\title{
GERAKAN SOSIAL FOLOWER TWITTER @Ridwan Kamil
}

\author{
Ira Dwi Mayangsari, Hutomo Ryan \\ Program Studi Ilmu Komunikasi Universitas Telkom \\ Email : iradwi@telkomuniversity.ac.id
}

\begin{abstract}
ABSTRAK
Penggunaan media sosial twitter dapat menghasilkan gerakan sosial untuk meningkatkan kesejahteraan masyarakat. Twitter walikota Bandung @Ridwan Kamil dengan 1 juta followers berusaha menghasilkan gerakan sosial di masyarakat. Penelitian melalui survey deskriptif memperlihatkan followers melakukan fungsi aktif (tweeting, tweeting dan menambah konten, mentioning dan mengirim direct message) dan pasif (searching, following, retweeting dan retweeting dan memberi konten tambahan) melalui twitter serta melakukan gerakan sosial dengan tingkat kategori efektif. Namun, hasil observasi memperlihatkan bahwa gerakan sosial yang dilakukan baru sekedar mensukseskan program yang disosialisasikan Ridwan Kamil, tidak ada kontinyuitas dan belum mengkritisi program yang ada.

Kata kunci : Fungsi aktif, fungsi pasif, twitter, gerakan sosial
\end{abstract}




\section{Pendahuluan}

Kemunculan media sosial sebagai media komunikasi yang menghasilkan gerakan sosial menjadi semakin popular. Twitter, yang muncul di 2006 telah digunakan untuk komunikasi debat politik, komunikasi krisis, marketing dan partisipasi kultural (Jones, 2014).

Munculnya penggunaan sosial media untuk gerakan sosial diawali dengan peristiwa Arab Spring, protes warga Mesir yang dimuat di The New York Times. Protes melalui twitter tersebut di legitimasi juga di media massa dan media warga (Harlow \& Johnson, 2011).

Penggunaan twitter untuk diskusi politik di tingkat lokal, daerah dan nasional pemilu di Australia, protes dan kegiatan mobilisasi di Tunisia, Mesir dan Yaman dan kasus Wikileasks memperlihatkan keberhasilan twitter dalam merubah kehidupan sosial. Dengan menggunakan symbol '\#' seperti '\#ausvotes' untuk pemilu Australia 2010, '\#londonriots' untuk koordinasi informasi dan debat politik diLondon atau '\#wikileaks' tentang rahasia pejabat publik, menjadi fenomena komunitas Twitter (Bruns \& Burgess, 2011).

Di Negara Meksiko, twitter pun berperan dalam mempengaruhi pemerintah membuat keputusan dan membentuk hubungan antara pemerintah, warga Negara, politisi dan berbagai stakeholder. Bahkan, generasi muda telah menggunakan sosial muda untuk mengkomunikasikan kepedulian, mengorganisasi protes ketika pemilu Presiden Meksiko 2012 (Sandoval-Almazan \& Gil-Garcia, 2013).

Penggunaan fungsi aktif twitter seperti "tweeting" mendukung pengguna untuk berperan aktif dalam pembuatan pesan dalam sosial media. Sementara penggunaan pasif melalui "following other users" dan "retweeting" juga penting dalam menyebarkan informasi ke follower (Ballard, 2011)

Di Indonesia, pejabat pemerintah juga menyadari pentingnya penggunaan twitter sebagai bagian dalam pelayanan ke masyarakat. Salahsatunya adalah akun twitter walikota Bandung, di periode 2013-2018, @ridwankamil yang memiliki followers 1.019.786 (Desember 2014).

\section{Metodologi}

Penelitian ini menggunakan metode survey deskriptif pada bulan Oktober 2014 sedangkan observasi dilakukan Desember 2014. Metode survey adalah penyelidikan yang diadakan untuk memperoleh fakta-fakta dari gejala-gejala yang ada dan mencari keteranganketerangan secara faktual. Populasi penelitian adalah followers @RK yang berjumlah 69.795 akun pada tanggal 17 Juni 2013 dan dengan menggunakan rumus Yamane diambil sampel sebesar 100 orang melalui teknik non probabilitas sampling. 
Validitas diuji dengan menggunakan uji korelasi Product Moment. Dari 27 pertanyaan, nilai $r$ hitung lebih besar dari $r$ tabel (0.3) sehingga dinyatakan valid. Sedangkan melalui uji Croncbach Alpha diperoleh skor 0.78 sehingga hasil penelitian reliabel.

\section{Twitter Ridwan Kamil (RK) dan Gerakan Sosial}

Responden penelitian ini adalah 100 followers RK yang bersedia mengisi angket online. Dari 100 responden, 43 pria dan 57 wanita dengan usia mayoritas 16-20 tahun (37\%), 21-25 (23\%), >25 (25\%) dan < 15 (15\%). Tingkat pendidikan 69\% lulusan SMA, S1 17\% dan Lainnya (12\%). Berdasarkan pekerjaan sebanayak 44\% mahasiswa, 26\% pelajar, $16 \%$ pegawai swasta, pegawai negeri $9 \%$, wirausaha $3 \%$. Pendapatan responden $40 \%$ berkisar $1-1.5 \mathrm{jt}$, $15 \%$ dengan pendapatan 1.5-2 juta, $16 \%$ lebih dari 2jt, $6 \%$ penghasilan di bawah 500rb dan terakhir $3 \%$ berpendapatan 500-1jt.

Berdasarkan jenis media yang digunakan dalam mengakses twitter sebesar 68\% menggunakan handphone/smartphone, 19\% computer, 11\% tablet dan 2\% PDA. Alasan menggunakan twitter adalah update info $26 \%$, informasi menarik $22,21 \%$ informasi kota, informasi lintas $17 \%$, menambah pengetahuan $12 \%$. Sedangkan melihat frekeunsi responden melihat timeline adalah 52\% responden melihat 1-2 kali sehari, sisanya 2-4 kali (26\%), 4-6 kali (15\%) dan sisanya $>6$ kali.

Dari data-data di atas terlihat bahwa followers RK 60\%nya adalah generasi muda di bawah 25 tahun yaitu pelajar dan mahasiswa kelas menengah - menengah atas, senang mengupdate dan mencari informasi namun mengakses twitter RK hanya sesekali dalam sehari.

Perilaku ber-twitter responden sebanyak $63 \%$ sering me-retweet, $42 \%$ me-mention $1-2$ kali dan 92\% menyukai informasi di twitter. Responden paling banyak memberi saran bahwa respon yang diberikan @ridwankamil harus lebih cepat yaitu sebesar 32\%, dan saran yang paling sedikit diutarakan yaitu harus lebih sering me-ReTweet sebesar $9 \%$.

Berikut adalah hasil angket yang menggunakan skala likert 1-2-3-4 (Sangat Tidak SetujuTidak Setuju-Setuju-Sangat Setuju) tentang kegiatan twit responden pada akun RK.

Tabel 1.1 Hasil Perhitungan Fungsi Aktif

\begin{tabular}{|c|c|c|}
\hline Pernyataan & $\begin{array}{l}\text { Total } \\
\text { skor }\end{array}$ & $\begin{array}{l}\text { Skor } \\
\text { Ideal }\end{array}$ \\
\hline \multirow{2}{*}{$\begin{array}{l}\text { Penerima tweeting dari Ridwan Kamil adalah warga yang } \\
\text { peduli terhadap pembangunan kota Bandung }\end{array}$} & 335 & 400 \\
\hline & \multicolumn{2}{|l|}{$83.75 \%$} \\
\hline \multirow{2}{*}{$\begin{array}{l}\text { Tweetingdari Ridwan Kamil mengajak agar followersnya } \\
\text { ikut mengawasi pelaksanaan kegiatan-kegiatan yang dibuat } \\
\text { oleh Ridwan Kamil }\end{array}$} & 272 & 400 \\
\hline & \multicolumn{2}{|l|}{$68.00 \%$} \\
\hline \multirow{3}{*}{$\begin{array}{l}\text { Tweeting dari Ridwan Kamil mengajak agar followersnya } \\
\text { berpartisipasi dalam kegiatan-kegiatan yang dibuat oleh } \\
\text { Ridwan Kamil }\end{array}$} & 306 & 400 \\
\hline & \multicolumn{2}{|l|}{$76.50 \%$} \\
\hline & 284 & 400 \\
\hline
\end{tabular}




\begin{tabular}{|c|c|c|}
\hline $\begin{array}{l}\text { Setujukah Anda jika dikatakan bahwa para followers akun } \\
\text { twitter Ridwan Kamil sadar untuk berpartisipasi dalam } \\
\text { kegiatan-kegiatan yang dibuat oleh Ridwan Kamil? }\end{array}$ & $71.00 \%$ & \\
\hline \multirow{2}{*}{$\begin{array}{l}\text { Tweeting dengan konten (foto,video,link,dll) dari Ridwan } \\
\text { Kamil mengajak agar followersnya berpartisipasi dalam } \\
\text { kegiatan-kegiatan yang dibuat oleh Ridwan Kamil }\end{array}$} & 314 & 400 \\
\hline & \multicolumn{2}{|l|}{$78.50 \%$} \\
\hline \multirow{2}{*}{$\begin{array}{l}\text { Tweeting dengan konten (foto,video,link,dll) dari Ridwan } \\
\text { Kamil mengajak agar followersnya ikut mengawasi } \\
\text { pelaksanaan kegiatan-kegiatan yang dibuat oleh Ridwan } \\
\text { Kamil }\end{array}$} & 314 & 400 \\
\hline & \multicolumn{2}{|l|}{$78.50 \%$} \\
\hline \multirow{2}{*}{$\begin{array}{l}\text { Saya melakukan partisipasi dengan melakukan tweeting } \\
\text { untuk mensosialisasikan kebijakan-kebijakan yang } \\
\text { dilakukan Ridwan Kamil }\end{array}$} & 288 & 400 \\
\hline & $72.00 \%$ & \\
\hline \multirow{2}{*}{$\begin{array}{l}\text { Saya melakukan partisipasi dengan melakukan tweeting } \\
\text { untuk complain sosialisasi kebijakan-kebijakan yang } \\
\text { dilakukan Ridwan Kamil }\end{array}$} & 278 & 400 \\
\hline & $69.50 \%$ & \\
\hline \multirow{2}{*}{$\begin{array}{l}\text { Saya melakukan partisipasi dengan memention orang lain } \\
\text { tentang kegiatan-kegiatan atau kebijakan-kebijakan yang } \\
\text { dibuat oleh Ridwan Kamil }\end{array}$} & 291 & 400 \\
\hline & \multicolumn{2}{|l|}{$72.75 \%$} \\
\hline \multirow{2}{*}{$\begin{array}{l}\text { Saya melakukan partisipasi dengan memention orang lain } \\
\text { atau Ridwan Kamil untuk complain tentang kegiatan- } \\
\text { kegiatan atau kebijakan-kebijakan yang dibuat oleh Ridwan } \\
\text { Kamil }\end{array}$} & 255 & 400 \\
\hline & \multicolumn{2}{|l|}{$63.75 \%$} \\
\hline \multirow{2}{*}{$\begin{array}{l}\text { Saya berpartisipasi dengan cara mengirimkan direct } \\
\text { message kepada orang laintentang kegiatan-kegiatan atau } \\
\text { kebijakan-kebijakan yang dibuat oleh Ridwan Kamil }\end{array}$} & 286 & 400 \\
\hline & \multicolumn{2}{|l|}{$71.50 \%$} \\
\hline \multirow{2}{*}{$\begin{array}{l}\text { Saya berpartisipasi dengan cara mengirimkan direct } \\
\text { message kepada orang lain atau Ridwan Kamil untuk } \\
\text { complain tentang kegiatan-kegiatan atau kebijakan- } \\
\text { kebijakan yang dibuat oleh Ridwan Kamil }\end{array}$} & 299 & 400 \\
\hline & \multicolumn{2}{|l|}{$74.75 \%$} \\
\hline Total Skor & \multicolumn{2}{|l|}{$73,46 \%$} \\
\hline
\end{tabular}

Dari hasil tabel perhitungan diatas diperoleh rata-rata skor sebesar $73,46 \%$ untuk sub variabel fungsi aktif yaitu fungsi tweeting, tweeting dan menambah konten (link, foto, video, lainnya), mentioning dan mengirim direct message. Pada garis kontinum Rank Order Mean posisi rata-rata skor tersebut berada pada interval 62,50\% hingga 81,25\% dengan kriteria efektif, ini menunjukkan bahwatwitter berperan secara aktif.

\section{Hasil Perhitungan Fungsi Pasif}

\begin{tabular}{|l|c|c|}
\hline Pernyataan & $\begin{array}{l}\text { Total } \\
\text { skor }\end{array}$ & $\begin{array}{c}\text { Skor } \\
\text { ideal }\end{array}$ \\
\hline $\begin{array}{l}\text { Saya melakukan searching yang menyangkut tentang } \\
\text { kegiatan atau kebijakan yang dibuat oleh Ridwan Kamil }\end{array}$ & \multicolumn{2}{|c|}{$\mathbf{7 0 . 2 5 \%}$} \\
\cline { 2 - 3 } $\begin{array}{l}\text { Saya berpartisipasi dengan cara melakukan } \\
\text { retweetingyang menyangkut tentang kegiatan atau }\end{array}$ & \multicolumn{2}{|c|}{$\mathbf{7 0 . 0 0 \%}$} \\
\cline { 2 - 3 } $\begin{array}{l}\text { kebijakan yang dibuat oleh Ridwan Kamil } \\
\text { Saya berpartisipasi dengan cara menambahkan konten } \\
\text { dalam melakukan retweeting yang menyangkut dengan } \\
\text { kegiatan atau kebijakan yang dibuat oleh Ridwan Kamil }\end{array}$ & \multicolumn{2}{|c|}{$\mathbf{7 3 . 5 0 \%}$} \\
\cline { 2 - 3 } Total Skor & \multicolumn{2}{|c|}{$\mathbf{7 1 , 2 5 \%}$} \\
\hline
\end{tabular}

\section{Sumber : Hasil Data Kuesioner}


Dari hasil perhitungan tabel diatas diperoleh rata-rata skor sebesar $69,70 \%$ untuk variabel fungsi pasif yaitu searching, following, retweeting dan retweeting dan memberi konten tambahan. Pada garis kontinum Rank Order Mean posisi rata-rata skor tersebut berada pada interval 62,51\% hingga $81,25 \%$ dengan kriteria efektif, ini menunjukkan bahwa responden menggunakan tweeter secara pasif hanya sekedar untuk pencarian informasi dengan cara following dan retweeting dari akun twitter Ridwan Kamil.

Hasil Perhitungan Gerakan sosial

\begin{tabular}{|c|c|c|}
\hline Pernyataan & $\begin{array}{l}\text { Total } \\
\text { skor }\end{array}$ & $\begin{array}{l}\text { Skor } \\
\text { ideal }\end{array}$ \\
\hline \multirow{2}{*}{$\begin{array}{l}\text { Saya pernah berpartisipasi dengan mengikuti program } \\
\text { kegiatan Ridwan Kamil (Contoh: Program Gerakan Sejuta } \\
\text { Biopori, Selasa Tanpa Rokok, dll) }\end{array}$} & 267 & 400 \\
\hline & \multicolumn{2}{|c|}{$66.75 \%$} \\
\hline \multirow{2}{*}{$\begin{array}{l}\text { Saya pernah berpartisipasi bergabung dengan organisasi } \\
\text { untuk membantu Ridwan Kamil membangun Bandung }\end{array}$} & 291 & 400 \\
\hline & \multicolumn{2}{|c|}{$\mathbf{7 2 . 7 5 \%}$} \\
\hline \multirow{2}{*}{$\begin{array}{l}\text { Saya pernah berpartisipasi ikut berdemonstrasi untuk } \\
\text { menyampaikan aspirasi kepada Ridwan Kamil }\end{array}$} & 283 & 400 \\
\hline & \multicolumn{2}{|c|}{$70.75 \%$} \\
\hline \multirow[t]{2}{*}{ Saya pernah memberi peringatan terhadap Ridwan Kamil } & 276 & 400 \\
\hline & \multicolumn{2}{|c|}{$69.00 \%$} \\
\hline \multirow[t]{2}{*}{ Saya pernah melakukan lobbying terhadap Ridwan Kamil } & 285 & 400 \\
\hline & \multicolumn{2}{|c|}{$71.25 \%$} \\
\hline \multirow{2}{*}{$\begin{array}{l}\text { Saya pernah berpartisipasi dengan menyampaikan } \\
\text { pendapat atau kritik kepada Ridwan Kamil }\end{array}$} & 296 & 400 \\
\hline & \multicolumn{2}{|c|}{$\mathbf{7 4 . 0 0 \%}$} \\
\hline \multirow{2}{*}{$\begin{array}{l}\text { Isi pesan yang disampaikan menggunakan bahasa yang } \\
\text { jelas dan mudah dimengerti. }\end{array}$} & 287 & 400 \\
\hline & \multicolumn{2}{|c|}{$71.75 \%$} \\
\hline \multirow{2}{*}{$\begin{array}{l}\text { Setujukah Anda, bahwa ketepatan waktu tweeting dari } \\
\text { Ridwan Kamil adalah faktor yang mendukung kefektivitasan } \\
\text { gerakan sosial dari para followersnya? }\end{array}$} & 293 & 400 \\
\hline & \multicolumn{2}{|c|}{$73.25 \%$} \\
\hline \multirow{2}{*}{$\begin{array}{l}\text { Setujukah Anda, jika penggunaan media "twitter" ini lebih } \\
\text { efektif dibandingkan media lain? }\end{array}$} & 288 & 400 \\
\hline & \multicolumn{2}{|c|}{$72.00 \%$} \\
\hline \multirow{2}{*}{$\begin{array}{l}\text { Setujukah Anda, jika media "twitter" ini tepat untuk } \\
\text { menjadi media komunikasi yang digunakan untuk } \\
\text { melakukan sosialisasi? }\end{array}$} & 285 & 400 \\
\hline & \multicolumn{2}{|c|}{$71.25 \%$} \\
\hline \multirow{2}{*}{$\begin{array}{l}\text { Setujukah Anda, jika media "twitter" ini tepat untuk } \\
\text { menjadi media yang digunakan untuk pengawasan } \\
\text { program dari pemerintah? }\end{array}$} & 295 & 400 \\
\hline & \multicolumn{2}{|c|}{$73.75 \%$} \\
\hline \multirow{2}{*}{$\begin{array}{l}\text { Setujukah Anda, bahwa penggunaan media "twitter" ini } \\
\text { dapat menarik perhatian para followers akun } \\
\text { twitterRidwan Kamil untuk berpartisipasi dalam kegiatan } \\
\text { yang dibuat oleh Ridwan Kamil? }\end{array}$} & 297 & 400 \\
\hline & \multicolumn{2}{|c|}{$74.25 \%$} \\
\hline \multirow{2}{*}{$\begin{array}{l}\text { Setujukah Anda, bahwa penggunaan media "twitter" ini } \\
\text { dapat menarik perhatian para followers akun twitter } \\
\text { Ridwan Kamil untuk mengawasi kegiatan atau kebijakan } \\
\text { yang dibuat oleh Ridwan Kamil? }\end{array}$} & 313 & 400 \\
\hline & \multicolumn{2}{|c|}{$75.42 \%$} \\
\hline Total Skor & \multicolumn{2}{|c|}{$63,01 \%$} \\
\hline
\end{tabular}

Sumber : Hasil Data Kuesioner

Dari hasil perhitungan tabel diperoleh rata-rata skor sebesar $63,01 \%$ untuk variabel gerakan sosial yang terdiri dari lobbying, organizational activity, contacting dan violence. Pada garis kontinum 
Rank Order Mean posisi rata-rata skor tersebut berada pada interval 62,51\% hingga $81,25 \%$ dengan kriteria efektif, ini menunjukkan bahwa tweet dari Ridwan Kamil dinilai ekektif dalam gerakan sosial.

Hasil Pengukuran Efektivitas Variabel Fungsi Penggunaan Twitter dan Variabel Gerakan sosial

\begin{tabular}{|c|c|c|c|}
\hline No. & Variabel Penelitian & Nilai & Kriteria Efektivitas \\
\hline 1. & Fungsi Penggunaan Twitter & & \\
\hline & a. Fungsi Aktif & $73.46 \%$ & Efektif \\
\hline & b. Fungsi Pasif & $71.25 \%$ & Efektif \\
\hline 2. & Gerakan Sosial & $63.01 \%$ & Efektif \\
\hline \multicolumn{2}{|c|}{ Total Skor } & $\mathbf{6 9 . 2 4 \%}$ & Efektif \\
\hline
\end{tabular}

\section{Sumber : Hasil Data Kuesioner}

Hasil mengenai pengukuran efektivitas diatas menunjukkan nilai dari variabel fungsi penggunaan twitter dan variabel partisipasi politik menunjukkan perolehan skor sebesar $68,72 \%$ . sedangkan paling rendah ditunjukan pada variabel gerakan sosial hanya sebesar $63,01 \%$ dibandingkan dengan indikator lainnya tetapi masih dalam batas garis kontinum dengan kriteria efektif, dan dapat diambil kesimpulan bahwa penggunaan twitter akun Ridwan Kamil efektif dalam pelaksanaan kegiatan gerakan sosial. Karena penggunaan twitter memiliki kekuatan yang cukup berpengaruh untuk membuat warga ikut andil dalam kegiatan politik yang dilaksanakan oleh Ridwan Kamil.

Secara umum, efektivitas komunikasi melalui akun twitter Ridwan Kamil sebagai media informasi, pengawas dan pelaksanaan kegiatan bagi followersnya atau warga Bandung sudah efektif. Komunikasi dikatakan efektif bila orang berhasil menyampaikan apa yang dimaksudkannya. Salah satu ukuran efektivitas komunikasi yaitu dengan cara melihat secara umum, komunikasi yang disampaikan dan dimaksudkan pengirim atau sumber, berkaitan erat dengan rangsangan yang ditangkap dan dipahami oleh penerima (Mulyana, 2000:22).

Dari hasil pengukuran efektivitas pada sub variabel fungsi aktif dan fungsi pasif menunjukkan perolehan skor sebesar $71,58 \%$ yang berada pada kriteria efektif, maka dapat disimpulkan bahwa twittermenjadi media komunikasi yang efektif dengan melihat pesan yang disampaikan oleh Ridwan Kamil melalui akun twitternya @ridwankamil telah sampai dengan baik ke khalayaknya dan mendapatkan rangsanagan yang baik juga berupa ikut berpartisipasinya warga terhadap kegiatan yang dilakukan.

\section{Media dan Gerakan Sosial}

Para followers RK sudah menyatakan keikutsertaannya pada berbagai gerakan sosial yang dicanangkan RK. Pengecekan gerakan sosial "\#Biopori Bandung" di twitter terlihat hanya ada 31 tweet dalam 2 tahun. Terdapat 3 tweet di Bulan Januari 2014, 24 tweet di Mei 2013, 2 tweet di 
bulan Maret 2013 dan 4 tweet di Januari 2013. Sebagian besar memperlihatkan foto-foto followers yang mengapilkasikan pembuatan biopori di lingkungannya (update Desember 2014).

Untuk melihat lebih dalam gerakan sosial yang lebih kritis, peneliti mengambil isu terkini di media massa yaitu isu trotoar di detik.com pada tanggal 14 November 2014 "Dewan Kritik Trotoar Granit di Bandung Terlalu Mahal dan Mewah" menyampaikan kritik Komisi C DPRD pada harga Rp 700 ribu rupiah per meter persegi. Ketua Komisi Entang Suryaman mengatakan seharusnya alokasi granit itu bisa dialihkan untuk penyelesaian banjir mengingat besarnya pengajuan dana gelondongan yang mencapai Rp 52 miliar. Berita selanjutnya "Ada Apa dengan Ridwan Kamil dan Dewan?" memperlihatkan ketidakoperatifan para anggota Komisi C DPRD yang diundang makan malam dan berdiskusi dengan RK, namun tidak dihadiri seorangpun.

Memperhatikan urgensi anggaran trotoar ini seharusnya followers RK mengkritisi juga melalui twitter. Ketika dicek dengan \#trotoar bandung terdapat hanya 5 tweet sepanjang 2014. Isi tweet di November meminta RK supaya trotoar bisa bersih dari papan iklan liar, protes trotoar digunakan sebagai tempat jualan. Di bulan Juli ada tweet meminta pengembalian fungsi trotoar di daerah Gegerkalong yang dijadikan tempat pemberhentian angkutan kota dan laporan trotoar amblas di daerah Kopo. Terakhir di April terdapat tweet positif tentang masih ada pohon rindang di trotoar kota Bandung.

Berdasarkan hal-hal di atas telihat bahwa aktivitas gerakan sosial yang dilakukan followers RK baru pada mensukseskan program RK dan dilakukan tidak kontinyutas, hanya euphoria di awal program. Mereka masih tidak upadate dengan berita terkini termasuk isu anggaran yang digunakan RK. Dapat dikatakan mereka belum melakukan gerakan sosial yang dapat menjadikan RK walikota yang lebih baik.

\section{Kesimpulan}

Twitter RK yang memiliki 1 juta followers efektif dalam melakukan komunikasi. Responden memiliki skor fungsi aktif sebesar 73,46\%, fungsi pasif $71,25 \%$, gerakan sosial $63,01 \%$ sehingga rata-rata skornya sebesar $69,24 \%$. Diperoleh data bahwa gerakan sosial yang dilakukan followers masih berupa euphoria program baru, tidak kontinyu dan tidak mengetahui isu terkini di media massa. Hal tersebut memperlihatkan tingkat media literacy para followers yang didominasi usia remaja ini masih rendah. 


\section{DAFTAR PUSTAKA}

Ballard, C. L. (2011). What's happening @Twitter: A uses and gratifications approach, 174. Retrieved from http://uknowledge.uky.edu/gradschool_theses/155

Bruns, A., \& Burgess, J. (2011). The use of Twitter hashtags in the formation of ad hoc publics. 6th European Consortium for Political Research General Conference, (August), 25-27. Retrieved from http://eprints.qut.edu.au/46515

Harlow, S., \& Johnson, T. J. (2011). The Arab Spring| Overthrowing the Protest Paradigm? How The New York Times, Global Voices and Twitter Covered the Egyptian Revolution. International Journal of Communication, 5, 16. Retrieved from http://ijoc.org/index.php/ijoc/article/view/1239

Jones, S. (2014). Twitter and Society. Peter Lang Publishing. New York.

Sandoval-Almazan, R., \& Gil-Garcia, J. R. (2013). Cyberactivism through social media:

Twitter, YouTube, and the Mexican political movement "I'm Number 132."

Proceedings of the Annual Hawaii International Conference on System Sciences, (132), 1704-1713. http://doi.org/10.1109/HICSS.2013.161 